\title{
Prenatal Diagnosis for Recessive Dystrophic Epidermolysis Bullosa in 10 Families by Mutation and Haplotype Analysis in the Type VII Collagen Gene (COL7A1)
}

\author{
Angela M. Christiano,* Sal LaForgia,* Amy S. Paller, ${ }^{\dagger}$ \\ Joseph McGuire, ${ }^{\neq}$Hiroshi Shimizu, ${ }^{\$}$ and Jouni Uitto* \\ *Departments of Dermatology and Cutaneous Biology, and \\ Biochemistry and Molecular Biology, Jefferson Medical College, and \\ Section of Molecular Dermatology, Jefferson Institute of Molecular \\ Medicine, Thomas Jefferson University, Philadelphia, Pennsylvania, \\ U.S.A. \\ ${ }^{+}$Children's Memorial Hospital, Northwestern University School of \\ Medicine, Chicago, Illinois, U.S.A. \\ ${ }^{\ddagger}$ Department of Dermatology, Stanford University Medical Center, \\ Palo Alto, California, U.S.A. \\ ${ }^{\S}$ Department of Dermatology, Keio University School of Medicine, \\ Tokyo, Japan
}

\begin{abstract}
Background: Epidermolysis bullosa (EB) is a group of heritable diseases that manifest as blistering and erosions of the skin and mucous membranes. In the dystrophic forms of EB (DEB), the diagnostic hallmark is abnormalities in the anchoring fibrils, attachment structures beneath the cutaneous basement membrane zone. The major component of anchoring fibrils is type VII collagen, and DEB has been linked to the type VII collagen gene (COL7Al) at $3 \mathrm{p} 2 \mathrm{l}$, with no evidence for locus heterogeneity. Due to life-threatening complications and significant long-term morbidity associated with the severe, mutilating form of recessive dystrophic EB (RDEB), there has been a demand for prenatal diagnosis from families with affected offspring.

Materials and Methods: Intragenic polymorphisms in COL7Al and flanking microsatellite markers on chro-
\end{abstract}

mosome 3p21, as well as detection of pathogenetic mutations in families, were used to perform PCR-based prenatal diagnosis from DNA obtained by chorionic villus sampling at 10-15 weeks or amniocentesis at 12-15 weeks gestation in 10 families at risk for recurrence of RDEB.

Results: In nine cases, the fetus was predicted to be normal or a clinically unaffected carrier of a mutation in one allele. These predictions have been validated in nine cases by the birth of a healthy child. In one case, an affected fetus was predicted, and the diagnosis was confirmed by fetal skin biopsy.

Conclusions: DNA-based prenatal diagnosis of RDEB offers an early, expedient method of testing which will largely replace the previously available invasive fetal skin biopsy at 18-20 weeks gestation.

\section{INTRODUCTION}

Epidermolysis bullosa (EB) is a group of heritable mechano-bullous diseases, which manifest as

Address correspondence and reprint requests to: Jouni Uitto, Department of Dermatology and Cutaneous Biology, Jefferson Medical College, 233 South 10th Street, Suite 450, Philadelphia, PA 19107, U.S.A. blistering and erosions of the skin and the mucous membranes as a result of minor trauma (1-3). The inheritance pattern can be either autosomal dominant or autosomal recessive. EB can be divided into three major general categories, based on the level of tissue separation within the cutaneous basement membrane zone separating the epidermis from the dermis (Fig. 1). In the 


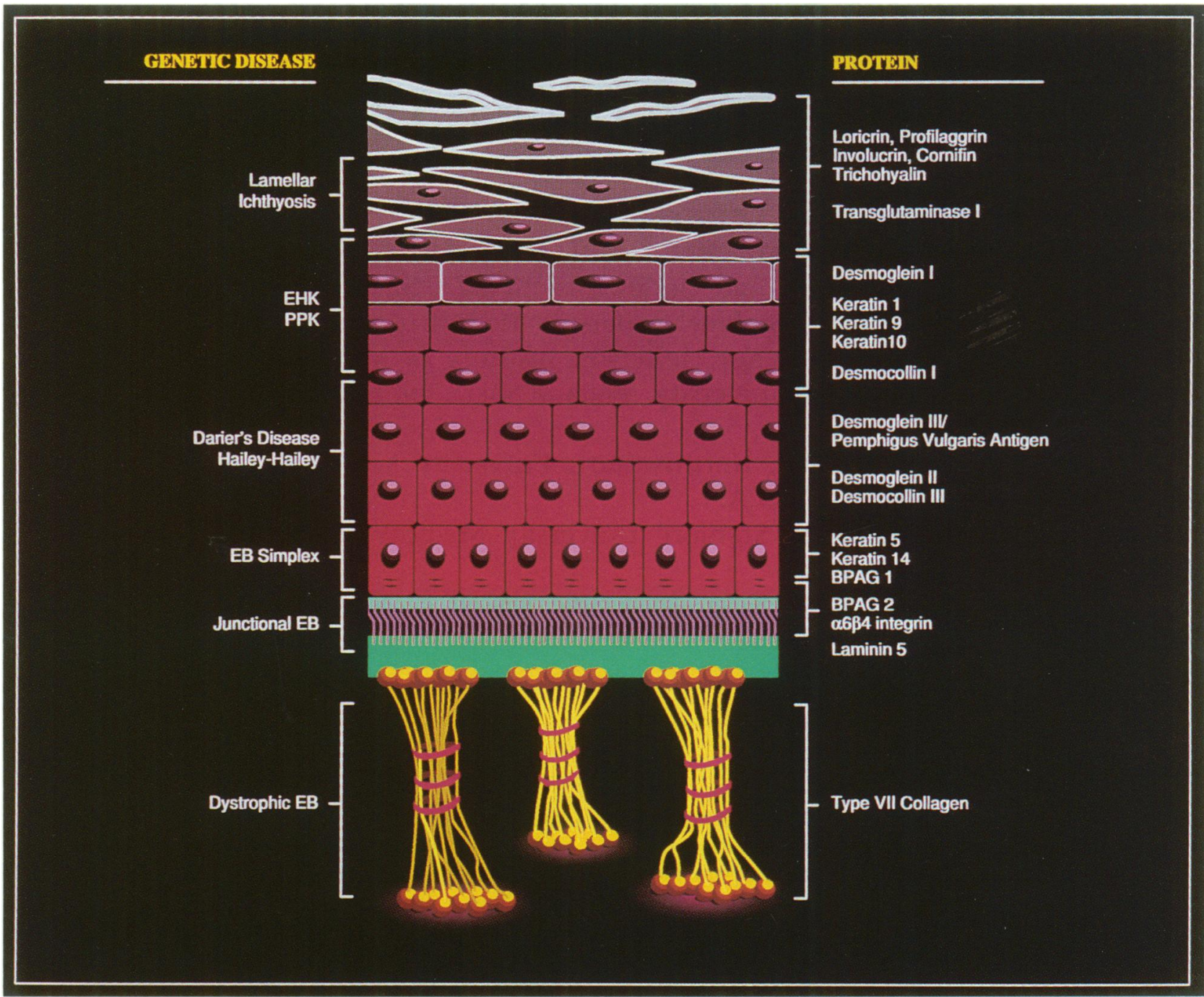

FIG. 1. Schematic representation of the epidermis and the underlying cutaneous basement membrane zone at the dermal-epidermal junction

The skin layers affected in heritable cutaneous diseases are indicated on the left, and the specific gene products are listed on the right. Note that tissue separation in the dystrophic forms of epidermolysis bullosa (EB) occurs below the basement membrane at the level of anchoring fibrils, which consist of type VII collagen. EHK, epidermolytic hyperkeratosis; PPK, palmoplantar keratoderma.

simplex forms, the tissue separation occurs within the basal keratinocytes as a result of mutations in keratins 5 and 14 (4). In the junctional forms of EB, the tissue separation occurs within the basement membrane itself, at the level of the lamina lucida, and mutations in the genes encoding the anchoring filament protein laminin 5 (previously known as kalinin/nicein) have recently been delineated (5-9). In the dystrophic, scarring forms of EB, the diagnostic hallmark is abnormalities in the anchoring fibrils, attachment structures extending from the basement membrane to the underlying dermis $(3,10)$. Anchoring fibrils are composed predominantly, if not exclusively, of type VII collagen, and recently a large number of mutations in the type VII collagen gene (COL7Al) have been disclosed in both the dominantly and recessively inherited forms of dystrophic EB $(9,11-16)$.

The spectrum of clinical severity of $\mathrm{EB}$ is highly variable (12). In the simplex forms, the blistering tendency can be relatively mild, often limited to hands and feet, and there is significant improvement with age. In contrast, in the most severe forms (the Herlitz type of junctional EB and the Hallopeau-Siemens type of recessive dystrophic EB), the disease can be lethal during the early postnatal period. Also, recessive dystro- 
phic EB (RDEB) is associated with extensive scarring, which can lead to severe mutilation of the hands and feet, esophageal stenosis, urogenital and gastrointestinal strictures, and corneal erosions. These complications lead to considerable morbidity, including malnutrition and anemia. Furthermore, patients with RDEB frequently develop aggressively metastasizing squamous cell carcinomas. As a result of these complications, the patients with RDEB often expire within the first four decades of life (12).

Because of the life-threatening complications and significant long-term morbidity associated with the most severe forms of EB, there has been a demand for prenatal diagnosis from families who have previously had an affected child, particularly those with severe, mutilating RDEB (17). Until last year, fetal skin biopsy was the only method of prenatal diagnosis available to families at risk for recurrence of RDEB. Initially, skin biopsies were performed by direct fetoscopic visualization, but more recent advances have utilized biopsy forceps under ultrasound guidance. Fetal skin can then be examined by electron microscopy for morphological abnormalities in anchoring fibrils and sublamina densa blister formation (18). This ultrastructural assessment may be supplemented by immunofluorescent antibody labeling of the dermal-epidermal junction using specific antibody probes (19). Although diagnosis of EB by fetal skin biopsy is reliable, fetoscopy carries a risk of fetal loss as high as $5 \%$, compared with a $1 \%$ loss rate following chorionic villus sampling and $0.5 \%$ following amniocentesis. Other potential complications include premature rupture of membranes and pre-term labor. Fetal skin biopsy is routinely performed between 18 and 20 weeks gestation, and if termination of pregnancy is elected, a late second trimester abortion carries greater risks. Accordingly, earlier diagnosis is preferable for ease of procedure and acceptance by patients.

As indicated above, recent advances in molecular biology have disclosed the underlying genetic defects in all three major forms of EB $(4,5,9)$. In particular, the dystrophic forms of EB are the result of mutations in COL7Al $(9-16,20)$. Furthermore, genetic linkage analyses utilizing intragenic polymorphisms have yielded no evidence for locus heterogeneity among over 40 families with RDEB, and over 10 families with DDEB reported thus far (20). These observations suggest, therefore, that all families with the dystrophic forms of EB are due to mutations in the COL7Al gene.
Recent cloning of the full-length type VII collagen cDNA (21), elucidation of the exonintron organization of the entire COL7Al gene (22), and fine mapping of the gene to human chromosome 3p21.1 (23) have provided the basis for development of DNA-based prenatal diagnosis for the dystrophic forms of EB. In this study, we report DNA-based first trimester determination of the fetal genotype in 10 families at risk for recurrence of the severe, recessively inherited form of dystrophic EB. The predictions were performed by analyzing the presence of specific mutations identified in the families, or by genetic linkage markers using fetal DNA obtained through chorionic villus sampling or by amniocentesis. The results demonstrate the feasibility of DNA-based diagnosis during the first trimester of pregnancy.

\section{MATERIALS AND METHODS Clinical Material}

This study included 10 families, all having previously had at least one affected child with RDEB. The diagnosis of RDEB was based on clinical presentation, light microscopy demonstrating subepidermal blistering, and diagnostic transmission electron microscopy revealing ultrastructural abnormalities in the anchoring fibrils (2). In most cases, direct immunofluorescence with an anti-type VII collagen monoclonal antibody, LH7:2, was also performed.

The families were evaluated by genetic counselors at the sites of fetal sampling, and all individuals signed informed consent for the research based diagnostic procedures. For analysis of the genotype underlying the RDEB phenotype, blood samples were obtained from the parents, the previously affected child, and whenever possible, from unaffected siblings. Fetal DNA samples were obtained in four cases by chorionic villus biopsy in the 10th-15th weeks of gestation, and in six cases through amniocentesis in the 12th-15th weeks of gestation. The chorionic villus samples and cells isolated from amniotic fluid were analyzed directly by polymerase chain reaction (PCR) amplification of COL7Al and flanking DNA sequences. In nine cases, fetal cells were also cultured, and the test was confirmed approximately 2 weeks later from the cultured fetal cells. 


\section{DNA Analyses}

DNA was isolated from peripheral blood using the standard phenol-chloroform extraction procedure (24). DNA from chorionic villus samples was obtained by initial extraction in buffer containing $8 \mathrm{M}$ urea, $0.3 \mathrm{M} \mathrm{NaCl}, 10 \mathrm{mM}$ Tris- $\mathrm{HCl}$ (pH 7.5), $10 \mathrm{mM}$ EDTA (pH 8.1), and $2 \%$ SDS, followed by phenol-chloroform-isoamyl alcohol extraction and precipitation with $0.5 \mathrm{M}$ ammonium acetate in isopropanol (24). Alternatively, cells were isolated from amniotic fluid by centrifugation at $10,000 \mathrm{rpm}$ for $30 \mathrm{~min}$, resuspended in buffer containing $0.5 \%$ SDS, $0.1 \mathrm{M} \mathrm{NaCl}, 50$ $\mathrm{mM}$ Tris ( $\mathrm{pH} 8.2$ ), $20 \mathrm{mM}$ EDTA ( $\mathrm{pH} \mathrm{8.1)}$, and $200 \mu \mathrm{g} / \mathrm{ml}$ proteinase $\mathrm{K}$. Samples were digested for $5 \mathrm{hr}$ at $56^{\circ} \mathrm{C}$, and DNA was extracted with phenol-chloroform-isoamyl alcohol, and precipitated with isopropanol.

\section{Mutation Identification}

Detection of pathogenetic mutations in the families with RDEB was performed by PCR amplification of COL7Al sequences, followed by electrophoretic heteroduplex analysis and dideoxynucleotide sequencing, as described elsewhere (13). The PCR primers and optimization conditions used in this study are summarized in Tables 1, 2, and 3. The presence of mutations in the affected individuals, as well as their inheritance from the parents, was verified by restriction endonuclease digestion when possible or by allele specific oligomer hybridizations (ASO) (Table 3). If a specific mutation was disclosed in one or both COL7Al alleles in the family, this information was used directly for prenatal testing. Nonpathogenetic polymorphic variants in the COL7Al gene were identified either by heteroduplex analyses or by restriction enzyme digestion (Table 2).

\section{Microsatellite Markers}

Microsatellite markers were also used for genotyping RDEB families. Microsatellite markers were chosen based on physical mapping studies using a panel of somatic cell hybrids recently accepted as framework hybrids by the human chromosome 3 mapping committee (25). This hybrid panel allows markers previously localized to human chromosome $3 \mathrm{p} 21$ to be segregated into three contiguous intervals. Two intervals flank the COL7Al locus at the telomeric and centromeric sides, while the remaining interval encompasses the COL7Al locus. D3S1029 and D3S1076 are highly informative microsatellite markers present in the telomeric and centromeric intervals, respectively, while D3S1235, D3S1573, and D3S1581 are found in the interval that includes the COL7Al locus. During efforts to completely characterize the interval containing the COL7Al locus, it was noted that D3S1581 was present on three independent $\mathrm{P} 1$ clones that also contain the COL7Al locus. As the insert size of $\mathrm{Pl}$ clones ranges from 85 to $100 \mathrm{~kb}$ and the COL7Al locus is $32 \mathrm{~kb}$, these data suggest that D3S1581 is less than $70 \mathrm{~kb}$ from the COL7Al locus.

Analysis of microsatellite markers was performed by end-labeling one primer using $\left[\gamma^{33} \mathrm{P}\right] \mathrm{dATP}$, and PCR consisting of $7 \mathrm{~min}$ at $95^{\circ} \mathrm{C}$, followed by 27 cycles of $95^{\circ} \mathrm{C}, 1 \mathrm{~min}, 60^{\circ} \mathrm{C}, 1 \mathrm{~min}$; $72^{\circ} \mathrm{C}, 1 \mathrm{~min}$; and electrophoresis in a $6 \%$ standard polyacrylamide gel. Microsatellite markers were visualized by exposure of the gel to autoradiography, and genotypes were assigned by visual inspection. In most cases, a combination of informative polymorphisms and mutations were used to ascertain the inheritance of COL7Al alleles from the parents to the fetus, and haplotype analyses were used for prenatal determination of the fetal genotype (Table 4).

\section{RESULTS}

\section{DNA-Based Prenatal Diagnosis of RDEB in 10 Families}

All families requesting prenatal diagnosis for RDEB presented to genetic counselors between 6 and 15 weeks gestation (Fig. 2). DNA samples from probands and family members were analyzed for the microsatellite markers D3S1029, D3S1235, D3S1573, D3S1076, and in some families D3S1581. In addition, mutation analysis and testing for the informativeness of intragenic COL7Al polymorphisms was initiated. Using this approach, we identified 11 COL7Al mutations in nine families, including eight premature termination codons, two glycine substitutions, and a putative splicing mutation (Fig. 3 and Table 4). Furthermore, each family was informative for several intragenic polymorphisms and/or flanking microsatellite markers (Tables 1, 2, and 3). Initial DNA studies were performed from chorionic villi or amniotic fluid cells, followed by a confirmatory DNA test from cultured fetal cells, to exclude maternal cell contamination. The re- 


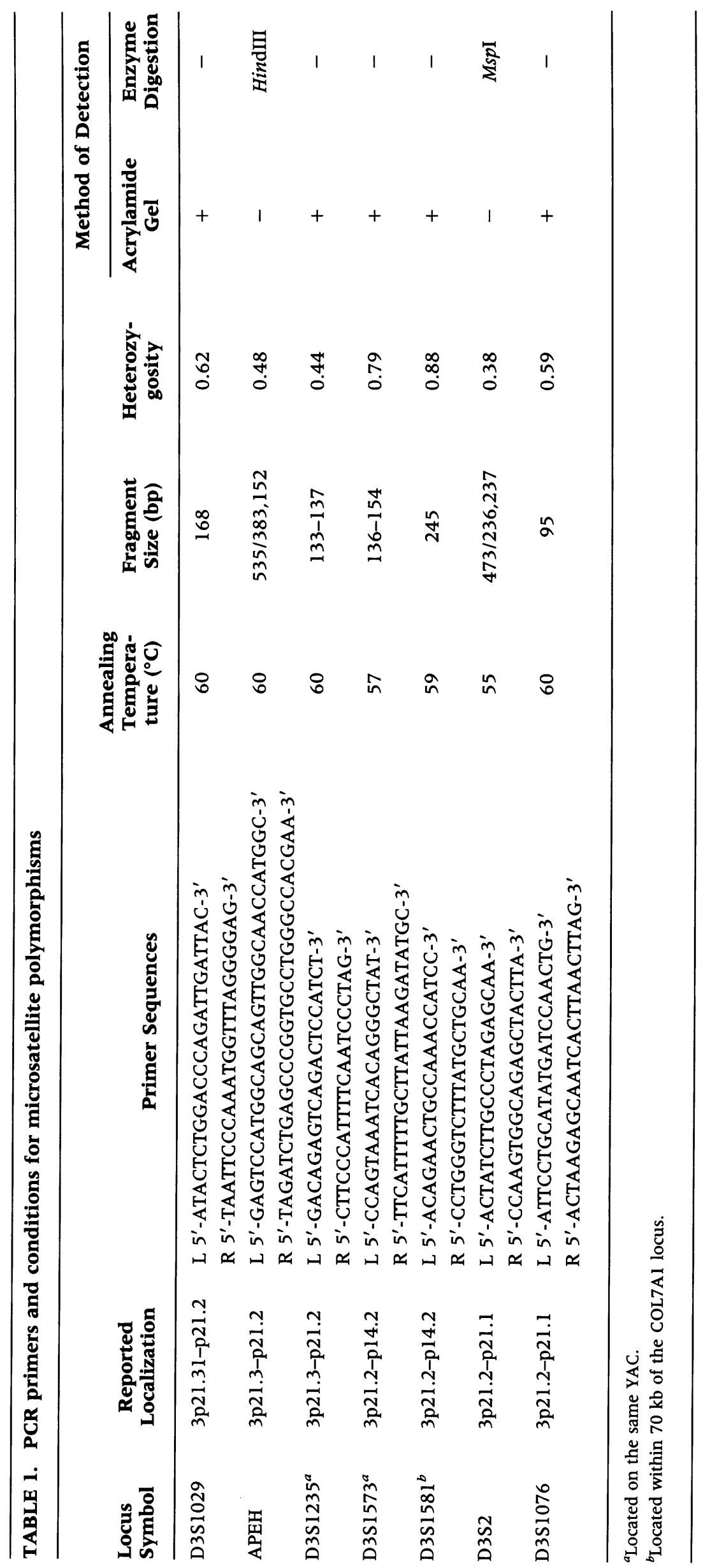




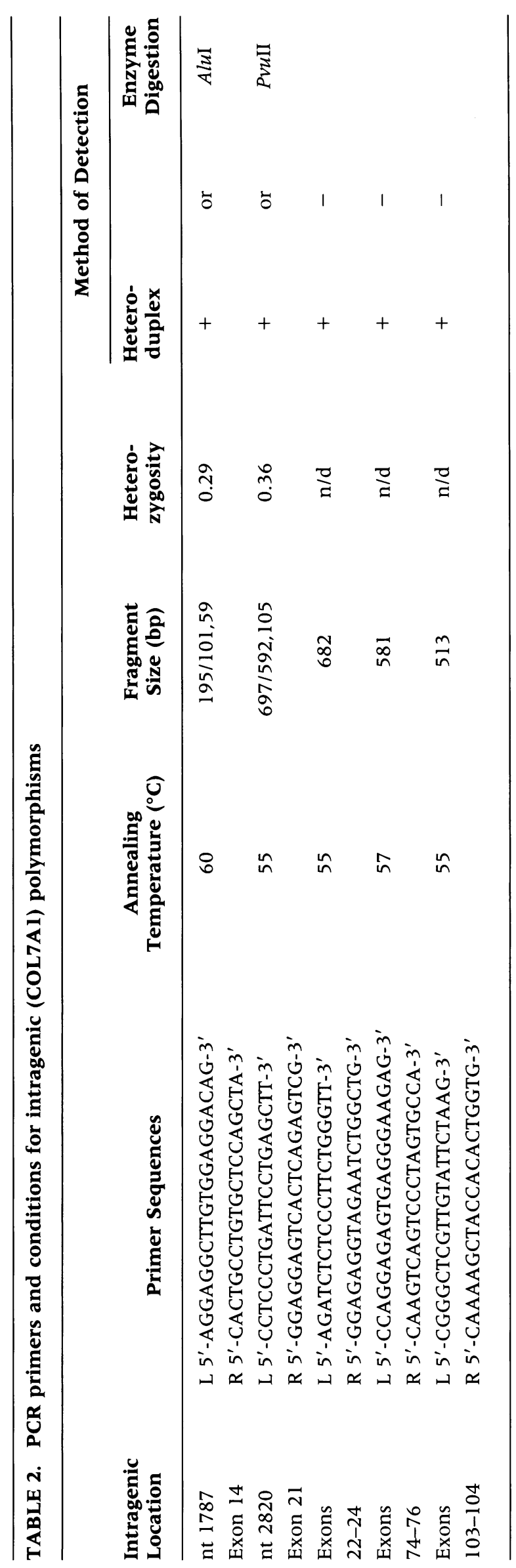




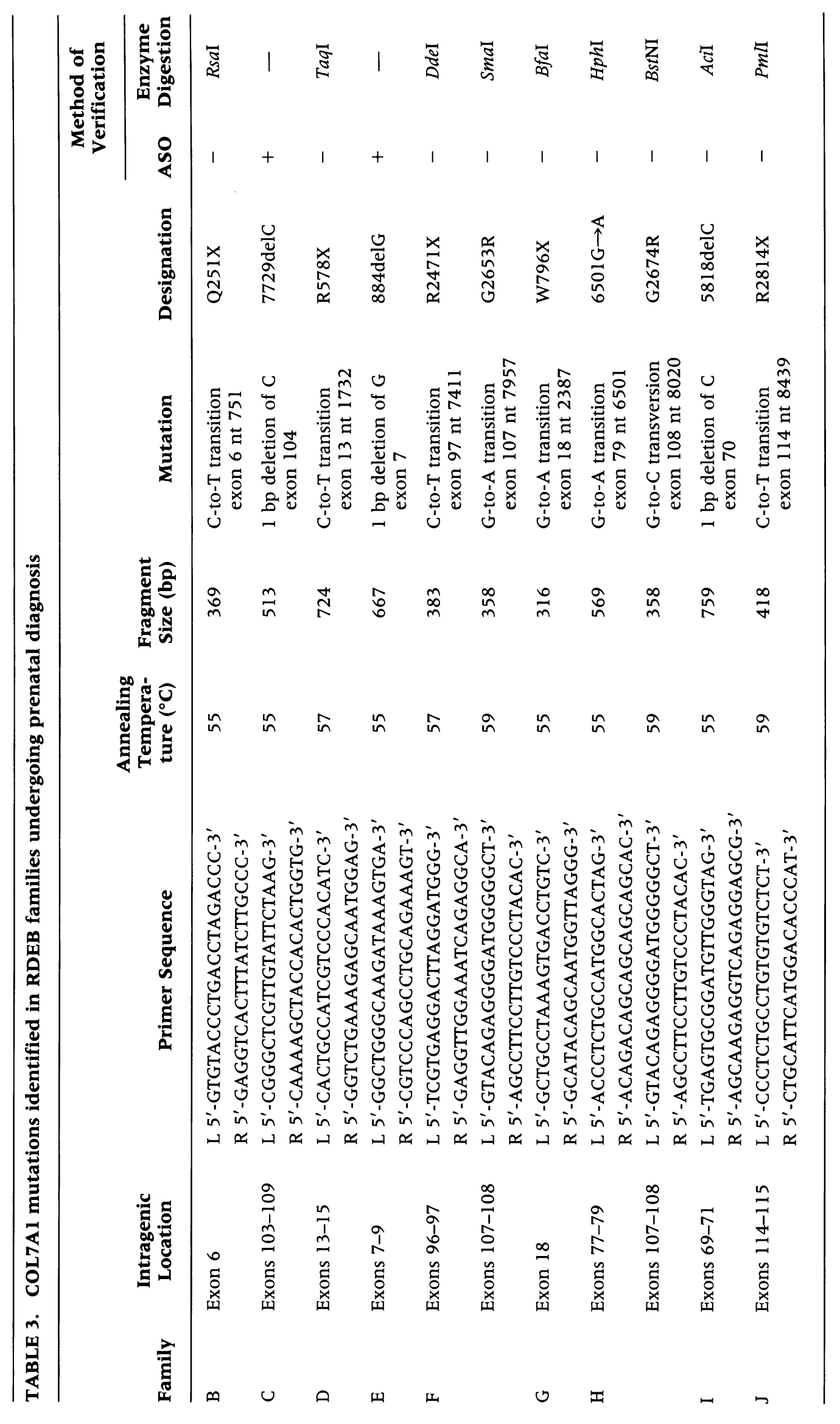


TABLE 4. Summary of results of ten cases of prenatal diagnosis of RDEB

\begin{tabular}{|c|c|c|c|c|c|}
\hline Family & $\begin{array}{l}\text { Ethnic } \\
\text { Origin }\end{array}$ & $\begin{array}{l}\text { Consan- } \\
\text { guinity }\end{array}$ & $\begin{array}{l}\text { Clinical Features } \\
\text { of the Proband }\end{array}$ & $\begin{array}{l}\text { Electron Microscopic } \\
\text { Findings }\end{array}$ & $\begin{array}{l}\text { Polymorphic } \\
\text { Markers }\end{array}$ \\
\hline A & Hispanic & - & $\begin{array}{l}\text { Bullae, scarring, } \\
\text { pseudosyndactyly }\end{array}$ & 一 & COL7Al/PvuII \\
\hline B & Afghani & + & $\begin{array}{l}\text { Pseudosyndactyly, } \\
\text { scarring, erosions, } \\
\text { absence of nails }\end{array}$ & $\begin{array}{l}\text { Sublamina } \\
\text { densa cleavage, } \\
\text { lack of AF }\end{array}$ & $\begin{array}{l}\text { COL7Al/PvuII } \\
\text { COL7Al/EX103-104 } \\
\text { D3S2 }\end{array}$ \\
\hline C & Caucasian & - & $\begin{array}{l}\text { Extensive blistering } \\
\text { with scarring, loss of } \\
\text { nails }\end{array}$ & $\begin{array}{l}\text { Sublamina } \\
\text { densa cleavage, } \\
\text { lack of AF }\end{array}$ & $\begin{array}{l}\text { D3S1029 } \\
\text { COL7A1/AluI } \\
\text { COL7A1/E22-24 } \\
\text { D3S2 } \\
\text { D3S1076 }\end{array}$ \\
\hline D & German & + & $\begin{array}{l}\text { Esophageal webbing, } \\
\text { blistering, scarring, } \\
\text { loss of nails }\end{array}$ & - & $\begin{array}{l}\text { D3S1029 } \\
\text { D3S1235 } \\
\text { COL7A1/PvuII } \\
\text { D3S2 }\end{array}$ \\
\hline $\mathrm{E}$ & Hispanic & - & $\begin{array}{l}\text { Blistering erosions on } \\
\text { trunk, groin, } \\
\text { extremities, scarring, } \\
\text { oncholysis }\end{array}$ & $\begin{array}{l}\text { Sublamina } \\
\text { densa cleavage, } \\
\text { lack of AF }\end{array}$ & $\begin{array}{l}\text { D3S1235 } \\
\text { COL7A1/E74-76 } \\
\text { D3S1076 }\end{array}$ \\
\hline $\mathrm{F}$ & $\begin{array}{l}\text { Portugese/ } \\
\text { Canadian }\end{array}$ & - & $\begin{array}{l}\text { Multiple blisters, } \\
\text { erosions, scarring, } \\
\text { oral erosions }\end{array}$ & $\begin{array}{l}\text { Sublamina } \\
\text { densa cleavage; } \\
\text { few hypoplastic AF }\end{array}$ & $\begin{array}{l}\text { D3F15S2 } \\
\text { COL7/PvuII } \\
\text { D3S2 }\end{array}$ \\
\hline G & Indian & + & $\begin{array}{l}\text { Pseudosyndactyly } \\
\text { erosions, scarring }\end{array}$ & - & COL7Al/PvuII \\
\hline $\mathrm{H}$ & Caucasian & - & $\begin{array}{l}\text { Esophageal webbing, } \\
\text { blistering, scarring, } \\
\text { erosions }\end{array}$ & $\begin{array}{l}\text { Sublamina } \\
\text { densa cleavage; } \\
\text { few hypoplastic AF }\end{array}$ & $\begin{array}{l}\text { D3S1029 } \\
\text { D3F15S2 }\end{array}$ \\
\hline I & Japanese & - & $\begin{array}{l}\text { Pseudosyndactyly, } \\
\text { extensive blistering }\end{array}$ & $\begin{array}{l}\text { Sublamina } \\
\text { densa cleavage, } \\
\text { lack of AF }\end{array}$ & $\begin{array}{l}\text { D3S } 1029 \\
\text { D3S1235 } \\
\text { D3S1573 } \\
\text { D3S } 1076\end{array}$ \\
\hline $\mathbf{J}$ & German & - & $\begin{array}{l}\text { Extensive scarring, } \\
\text { blistering, erosion, } \\
\text { loss of nails, } \\
\text { esophageal stricture }\end{array}$ & 一 & $\begin{array}{l}\text { D3F15S2 } \\
\text { COL7A1/PvuII } \\
\text { COL7A1/E22-24 } \\
\text { D3S2 }\end{array}$ \\
\hline
\end{tabular}

sults of genotype analysis of the 10 fetuses resulted in prenatal exclusion of RDEB in nine cases, and diagnosis of RDEB in one case. The latter finding was confirmed by fetal skin biopsy (Table 4).

FAMILY A. Family A consisted of unrelated, unaffected parents of Hispanic origin and a 4-yearold female who was noted at birth to have bullae on the lower extremities. She subsequently displayed characteristic clinical features of RDEB, including extensive scarring of the skin, pseudosyndactyly of the hands and feet, and corneal erosions. The mother presented in the 12 th gestational week requesting prenatal diagnosis. PCR-based analysis of DNA derived from peripheral blood leukocytes revealed that the parents were heterozygous for the PvuII restriction frag- 


\begin{tabular}{|c|c|c|c|c|}
\hline $\begin{array}{l}\text { Mutation-Bearing } \\
\text { Heteroduplex }\end{array}$ & $\begin{array}{l}\text { COL7Al Mutation(s) } \\
\text { in Proband }\end{array}$ & $\begin{array}{l}\text { Method of } \\
\text { Sampling }\end{array}$ & $\begin{array}{l}\text { Genotypic } \\
\text { Prediction }\end{array}$ & $\begin{array}{l}\text { Clinical } \\
\text { Outcome }\end{array}$ \\
\hline - & - & 13 week CVS ${ }^{a}$ & Carrier & Healthy \\
\hline COL7Al/E6 & Q251X/Q251X & $\begin{array}{l}14 \text { week } \\
\text { amniocentesis }\end{array}$ & Carrier & Healthy \\
\hline COL7Al/E103-104 & 7729delC & 10 week CVS & Carrier & Healthy \\
\hline COL7Al/E13-15 & R578X/R578X & $\begin{array}{l}14 \text { week } \\
\text { amniocentesis }\end{array}$ & Carrier & Healthy \\
\hline COL7Al/E7-9 & 884delG & $\begin{array}{l}14 \text { week } \\
\text { amniocentesis }\end{array}$ & Carrier & Healthy \\
\hline $\begin{array}{l}\text { COL7A1/E96-97 } \\
\text { COL7A1/E107-108 }\end{array}$ & R2471X/G2653R & $\begin{array}{l}15 \text { week } \\
\text { amniocentesis }\end{array}$ & Carrier & Healthy \\
\hline COL7A1/E18 & W796X/W796X & 15 week CVS & Normal & Healthy \\
\hline $\begin{array}{l}\text { COL7Al/E77-79 } \\
\text { COL7A1/E107-108 }\end{array}$ & $6501 \mathrm{G} \rightarrow \mathrm{A} / \mathrm{G} 2674 \mathrm{R}$ & $\begin{array}{l}11 \text { week } \\
\text { amniocentesis }\end{array}$ & Carrier & Healthy \\
\hline COL7A1/E69-71 & 5818delC & $\begin{array}{l}16 \text { week } \\
\text { amniocentesis }\end{array}$ & Affected $^{b}$ & $\begin{array}{l}\text { Electively } \\
\text { terminated }\end{array}$ \\
\hline COL7Al/E114-115 & $\mathrm{R} 2814 \mathrm{X} / \mathrm{R} 2814 \mathrm{X}$ & 11 week CVS & Normal & Healthy \\
\hline
\end{tabular}

${ }^{a} \mathrm{CVS}$, chorionic villus sampling.

${ }^{b_{f}}$ etal skin biopsy performed.

ment length polymorphism (AB genotype) (26). The previously affected 4-year-old girl had inherited both A alleles (AA genotype). Analysis of fetal DNA obtained by chorionic villus sampling in the 13th week gestation revealed a heterozygous $\mathrm{AB}$ genotype, predicting that the fetus was a clinically normal heterozygous carrier (Fig. 2A). The pregnancy was carried to term, and a healthy female infant was born in October 1993.
Careful examination of the newborn revealed no evidence of a blistering disease, and subsequent follow-up has not revealed any skin problems.

FAMILY B. Family B consisted of a female with RDEB, who was the $8-\mathrm{lb}, 12-\mathrm{oz}$ product of a term, uncomplicated pregnancy from a consanguineous mating in which the parents were halffirst cousins of Afghani origin (Fig. 2B). The pro- 
band also had an older, clinically unaffected brother. At the time of delivery of the proband, numerous blisters and erosions were noted on the extremities, back, and the tongue, and new lesions continued to develop in a generalized distribution. Electron microscopic examination of a skin biopsy showed cleavage beneath the lamina densa associated with a lack of anchoring fibrils, and weak immunofluorescent staining for type VII collagen epitopes at the dermoepidermal junction. These features confirmed the diagnosis of dystrophic EB. At the age of 5 years, generalized hypertrophic and atrophic scars, extensive milia, and erosions of the buccal mucosa and tongue were noted. There was pseudosyndactyly of the toes of the right foot, and a complete absence of the nails.

The mother of the affected child presented at the 9th week of gestation requesting prenatal diagnosis. Due to sociocultural factors, including a month-long religious holiday and unavailability of a female obstetrician at the HMO to perform chorionic villus biopsy, amniocentesis was not performed until the 14th week of gestation. Linkage analysis using the intragenic PvuII polymorphism and a flanking polymorphic marker (D3S2) detectable by $M s p I$ endonuclease digestion, as well as a heteroduplex shift in intron 103 of COL7Al reflecting a normal single base polymorphism, were used for haplotype analysis. Subsequent mutational analysis revealed a homozygous nonsense mutation (Q251X) in exon 6 (Fig. 3). A combination of these markers allowed prediction of a clinically unaffected female fetus who was heterozygous carrier of the maternal mutation (Fig. 2B). A healthy female infant was born in September 1994. Examination of her skin has not revealed any evidence of a blistering disease.

FAMILY C. Family C consisted of a 2-year-old male who was noted at birth to have extensive blistering, and the diagnosis of RDEB was made by transmission electron microscopy, which demonstrated sublamina densa tissue separation with complete absence of anchoring fibrils, both in the lesional and perilesional skin. The unrelated parents were clinically unaffected, and there were no other children. The mother presented to a genetic counselor in the 8th week of gestation requesting prenatal diagnosis. At that point, blood samples were obtained from the parents and the previously affected child. Intragenic polymorphisms detectable by AluI endonuclease digestion (26) and by heteroduplex anal- ysis of the COL7Al segment encompassing exons 103-104 were found to be informative. Subsequently, the maternal mutation was delineated (7729delC) in exon 104, resulting in a frameshift and premature termination codon downstream from the site of the deletion. In addition, three flanking markers (D3S1029, D3S2, and D3S1076) were used for haplotype analysis. No recombination between any of these markers and the COL7Al locus was detected in this family. Chorionic villus sampling was performed in the 10th week of gestation, and genetic information based on the family haplotype analysis and the exclusion of the maternal mutation allowed the prediction of a clinically normal fetus (Fig. 2C). A healthy female infant was delivered in December 1994, with no evidence of skin blistering.

FAMILY D. Family D consisted of a 2-year-old female severely affected with RDEB. The parents were clinically unaffected first cousins of German ancestry. The mother presented in the 6th week of pregnancy requesting prenatal diagnosis. Blood samples were obtained from the parents and the proband with RDEB. Initial chorionic villus sampling was performed in the 11 th week of gestation in a mobile ambulatory obstetric unit in a Midwestern region of the United States. Analysis of the chorionic villus specimen, in comparison with the haplotype of the nuclear family, suggested that the sample obtained was of maternal origin. Subsequently, amniocentesis was performed in the 15 th week of gestation. Utilization of the intragenic PvuII polymorphism and the flanking marker D3S2, together with two flanking microsatellite markers (D3S1029 and D3S1235), predicted that the fetus was a female carrier of the paternal allele, thus predicting a clinically unaffected child (Fig. 2D). Subsequently, a homozygous nonsense mutation (R578X) in exon 14 was delineated in the affected proband. A healthy female infant was born in January 1995.

FAMILY E. Family E consisted of an 11-monthold Hispanic female who was noted at birth to have extensive bullae and erosions on the trunk, groin, and extremities. Also, erosions on the lips and oral mucosa were noted. Examination at 11 months of age revealed patches of atrophic, hypopigmented skin, with milia. There was marked onycholysis, and loss of nails in two digits on each hand and foot was noted. The diagnosis of DEB was confirmed by light microscopy, which showed a subepidermal tissue separation, and 
direct immunofluorescence demonstrating type IV collagen epitopes in the roof of the blister. Transmission electron microscopy failed to reveal any clearly recognizable anchoring fibrils, either in the area of blisters or in the perilesional skin. The parents were clinically unaffected, and the affected daughter had two clinically unaffected older brothers. The mother presented to a genetic counselor in the 10th week of pregnancy requesting prenatal diagnosis. Analysis of the DNA obtained from blood samples from the parents, and the three previously born children revealed that a telomeric microsatellite (D3S1029), a centromeric microsatellite (D3S1076), and a closely linked microsatellite (D3S1235) marker were all informative in this family. Furthermore, heteroduplex shifts in both the maternal and paternal COL7Al alleles were used for prenatal diagnosis. The paternal heteroduplex was subsequently shown to reflect a specific mutation (884delG) in exon 7 of COL7Al. The maternal mutation was not disclosed at the time of the prenatal diagnosis. Amniocentesis was performed by genotype analysis and mutation detection in this family. The results were consistent with the fetus having not inherited the paternal mutation $884 \mathrm{delG}$, but being a clinically unaffected male carrier of the maternal EB allele (Fig. 2E). A healthy male infant was born in February 1995.

FAMILY F. Family $\mathrm{F}$ consisted of a $\mathrm{l}$-year-old male who was noted at birth to have skin missing on the left thumb and both feet, and have multiple blisters on the fingers. At 6 months of age, extensive scarring was noted on the legs and shins, nails from the big toes were missing on both feet, and there were erosions in the mouth and cheeks. The parents were clinically unaffected, and there were no other children. The initial clinical diagnosis was a dystrophic form of EB, possibly Bart syndrome (2). The diagnosis of DEB was confirmed by diagnostic electron microscopy, which revealed the presence of hypoplastic anchoring fibrils and separation of the epidermis beneath the dermal-epidermal basement membrane. Epitope mapping revealed that bullous pemphigoid antigen and type IV collagen, components of the dermal-epidermal basement membrane (see Fig. 1), were along the roof of the blister, confirming sublamina densa separation. However, type VII collagen was present in apparently normal amounts at the dermal-epidermal junction in perilesional skin and in the roof of the blisters. These findings were inter- preted to be consistent with a dystrophic form of $\mathrm{EB}$, possibly the mitis variant of generalized RDEB, although a new dominant mutation could not be excluded on the basis of these morphologic observations. However, subsequent genetic analyses of COL7Al revealed pathogenetic mutations in both alleles, confirming a recessive form of DEB. The father was shown to be carrier of a nonsense mutation, R2471X, while the mother was shown to have a missense mutation, G2563R. In addition to these mutations, two flanking polymorphisms (D3S2 and D3F15S2) were informative in the family. The mother presented to a genetic counselor in the 9th week of gestation, and requested prenatal diagnosis. Amniocentesis was performed in the 15th week of gestation. Analysis of the fetal DNA predicted that the fetus is a clinically unaffected male carrier of the paternal mutation, R2471X (Fig. 2F). Specifically, the fetus did not carry the maternal mutation, and the flanking polymorphisms were consistent with this conclusion. A healthy male infant was born in March 1995.

FAMILY G. Family G consisted of an 8-year-old male severely affected with RDEB. The parents, who were clinically unaffected, were first cousins of Indian origin, and the union had also resulted in three previous miscarriages. Another branch of the family consisted of unaffected cousins who were parents of three children affected with RDEB, all of whom had died from complications of the disease. The latter mating had produced two clinically unaffected daughters.

The mother of the affected 8-year-old male with RDEB presented to a genetic counseling unit in India in the 1 lth week of gestation, and requested prenatal diagnosis. Analysis of the intragenic PvuII polymorphism indicated that both parents were heterozygous for this polymorphism ( $\mathrm{AB}$ genotype). The previously affected child was homozygous for presence of the PvuII polymorphism (BB genotype). DNA from the fetus obtained from a chorionic villus sample in the 15 th week of gestation revealed that the fetus was homozygous for the absence of the PvuII polymorphism (AA genotype), thus predicting a phenotypically healthy female (Fig. 2G). A healthy female infant was born in March 1995.

FAMILY H. Family $\mathrm{H}$ consisted of a 2-year-old female affected with RDEB. The clinical features included esophageal webbing and widespread blistering and erosions of the skin over sites of trauma. The immunofluorescence antigenic map- 
A.

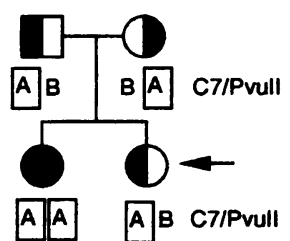

B.

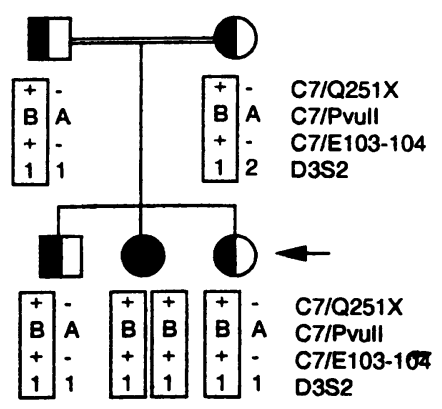

c.

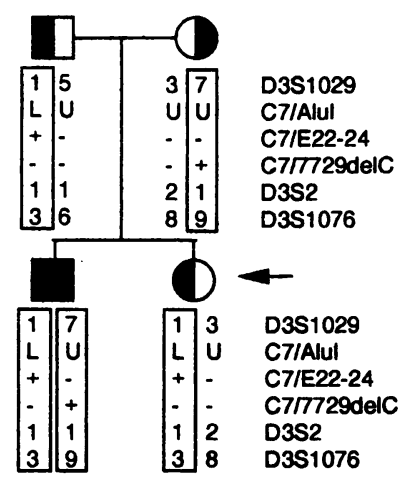

D.

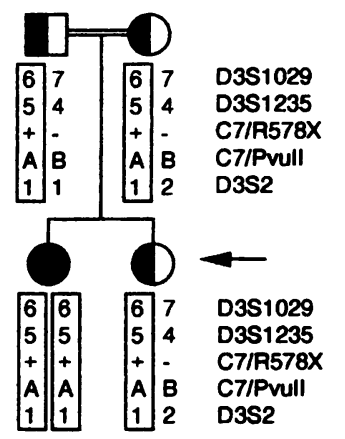

E.

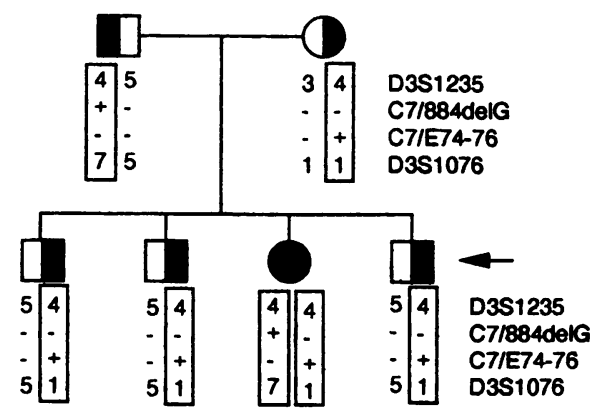

F.

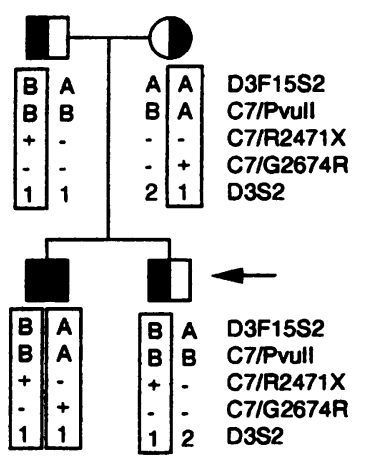

I.

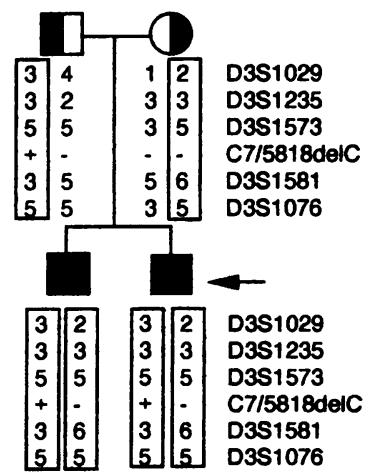

G.

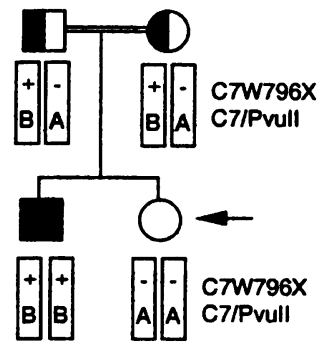

H.

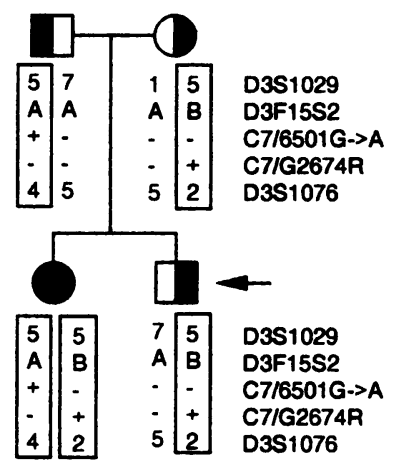

J.

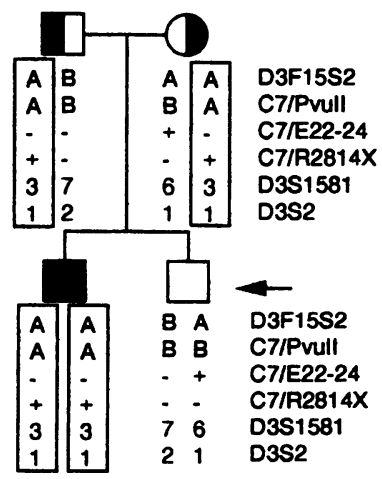




\section{FIG. 2. Pedigrees of the ten families included in this study}

Squares indicate males, circles represent females, filled shapes indicate affected individuals, and half-filled shapes indicate carriers. A double line between shapes is indicative of consanguinity. Arrows indicate individuals genotyped for prenatal diagnosis. The haplotypes of the mutant alleles are boxed. D3S1029, D3F15S2, D3S1235,

D3S1573, D3S1076, and D3S2 are polymorphic markers of 3p21. C7/PvulI, intragenic PvuII polymorphism; C7/ Alul, intragenic AluI polymorphism; C7/E22-24, C7/E74-76, and C7E103-104, heteroduplexes in the region of type VII collagen gene exons 22-24, 74-76, and 103-104, respectively. All other C7 designations refer to the mutation in COL7Al in the family (Table 2).

ping study indicated that bullous pemphigoid antigen, laminin 1, type IV collagen, and type VII collagen epitopes were expressed along the roof of a subepidermal blister. These findings were consistent with the diagnosis of DEB. The parents were clinically unaffected, and there were no other children. The mother presented for prenatal diagnosis at 6 weeks of gestation. DNA analysis of the parents and previously affected child revealed that two flanking polymorphisms (D3F15S2 and D3S2) were informative. Furthermore, heteroduplex analysis revealed distinct shifts in a maternal and a paternal COL7Al allele, which were subsequently shown to reflect distinct mutations. Specifically, the paternal mutation $(6501 \mathrm{G} \rightarrow \mathrm{A})$ affects the splice site at the $3^{\prime}$ end of exon 79 , predicting aberrant splicing. The maternal mutation consists of a missense substitution of a glycine by an arginine (G2674R). Amniocentesis was performed in the 11 th week of gestation, and analysis of the fetal DNA predicted a male carrier fetus lacking the pa- ternal mutation (Fig. 2H). A healthy male infant was born in April 1995.

FAMILY I. Family I presented with a 1-year-old Japanese male with typical clinical features of RDEB with severe fusion of the toes and fingers. The parents were clinically unaffected, and there were no other offspring. The diagnosis of RDEB was confirmed by diagnostic electron microscopy, which demonstrated tissue separation just beneath the lamina densa, and there were no mature anchoring fibrils. Indirect immunofluorescence revealed normal expression of the bullous pemphigoid antigen, type IV collagen, laminin 5 (GB3), and type VII collagen (LH7.2) epitopes in the roof of the blister.

Molecular analysis of the COL7Al gene in this family indicated that four microsatellite markers (D3S1029, D3S1235, D3S1076, and D3S1573) were informative. However, the intragenic PvuII and the flanking polymorphisms

FIG. 3. Mutation analysis in Family $B$

The nuclear family, shown on the top of Frame A, consists of unaffected, related parents who have an older unaffected son, an affected daughter, and a younger daughter $(*)$ who was predicted by prenatal testing to be clinically unaffected. (A) Heteroduplex analysis of the family members revealed a band with altered mobility in Lanes 1, 2, 4, and 5, com-

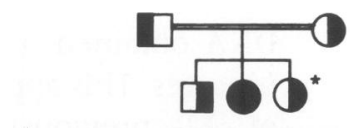

A

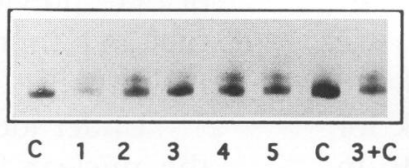

C

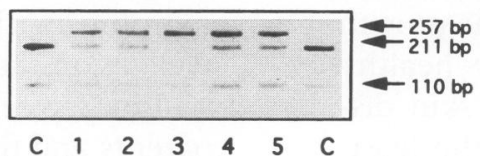

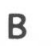

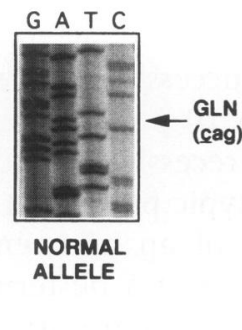

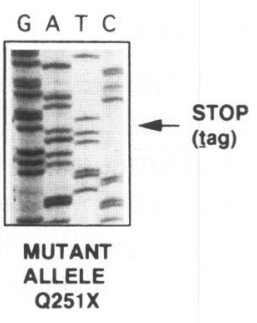

pared with normal, unrelated controls (C). The previously affected child (Lane 3) did not show a band of altered mobility due to homozygosity for the mutation; however, when the PCR product from the patient was mixed with a control product $(3+\mathrm{C})$, a shift similar to those seen in the parents and two other unaffected siblings was noted. (B) Sequencing of the mutant allele, in comparison to normal allele, revealed a C-to-T transition which resulted in substitution of a glutamine codon (CAG) by a premature termination codon (TAG). (C) The presence of the mutation, Q251X, was verified at the genomic level by the loss of an RsaI site. Digestion of PCR-amplified genomic DNA revealed the presence of two bands, 211 and $110 \mathrm{bp}$ (as well as a $46 \mathrm{bp}$ band which is not shown) in normal control individuals $(\mathrm{C})$. The proband (Lane 3 ) was shown to be homozygous for the loss of the restriction enzyme site, while individuals shown in Lanes $1,2,4$, and 5 were heterozygous for the mutation. 
(D3S2 and D3F15S2) were not informative. In addition, the father was shown to be heterozygous for a $1 \mathrm{bp}$ deletion of a $\mathrm{C}$ in exon 70 of COL7Al (5818delC). This information was used for prenatal prediction from DNA sample obtained by amniocentesis at 16 weeks of gestation (Fig. 2I). The analysis indicated that the fetus was affected with RDEB. Fetal skin biopsy was performed at 20 weeks gestation, and revealed sublamina densa cleavage, consistent with RDEB, and the pregnancy was electively terminated.

FAMILY J. Family J consisted of an 11-year old male with typical features of RDEB. The parents were clinically unaffected and unrelated; however, they were both of German ancestry. The mother presented in the 10th week of gestation requesting prenatal diagnosis. Linkage analysis revealed that the family was fully informative for the PvuII polymorphism in COL7A1, and partially informative for the flanking markers D3S2 and D3F15S2. Heteroduplex analysis also revealed a unique and identical shift in both parents, in the PCR fragment spanning exons 114 and 115 of COL7A1, for which the affected child was homozygous. Sequence analysis revealed a C-to-T transition at nt 8440 , resulting in a nonsense mutation at amino acid 2814 of COL7Al $(\mathrm{R} 2814 \mathrm{X})$. Analysis of chorionic villi obtained the following week revealed the fetus to be an unaffected male carrying neither of the parental mutant alleles (Fig. 2J). A healthy male infant was born in July 1995.

\section{DISCUSSION}

\section{Feasibility of DNA-Based Prenatal Testing for RDEB}

This study reports successful determination of the fetal genotype in 10 pregnancies at risk for recurrence of severe recessive dystrophic EB. In nine cases, the genotypic prediction has proven correct by the birth of an apparently healthy child with no evidence of a blistering skin disease. These observations demonstrate the feasibility of DNA-based prenatal testing in families at risk for this devastating skin disease.

The approaches taken in this study consisted of utilization of intragenic or flanking polymorphisms, microsatellite analysis, direct mutational analysis, or a combination of these approaches for haplotype analysis. The candidate gene in the dystrophic forms of EB is COL7Al, and no evi- dence of locus heterogeneity has been found thus far $(9,27,28)$. Furthermore, recent studies have disclosed over 50 distinct mutations in the COL7Al gene in families either with recessively or dominantly inherited form of dystrophic EB (11-16). This information provides the basis for the use of haplotype analysis by informative polymorphisms for prenatal testing of RDEB. It should be noted, however, that most of the families tested for RDEB had only one previously affected child. One of the potential pitfalls of the haplotype analysis using polymorphic markers is the possibility of a de novo mutation or a parental germline mosaicism in one of the alleles inherited by the previously affected offspring. For this reason, the prenatal testing should, if possible, be based on direct demonstration of the presence or absence of the mutations in both COL7Al alleles. Towards this goal, we recently cloned the entire human COL7Al gene (21), elucidated the exon-intron organization (22), and developed PCR strategy that allows amplification of all 118 exons. PCR amplification products are then routinely examined for putative mutations by heteroduplex scanning, which has been shown to reliably detect single-base substitutions, insertions, or deletions within the gene. A complete heteroduplex profile of the COL7A1 alleles from the parents, and a previously affected child can be obtained within 72 hours. If bands of altered mobility in the heteroduplex analysis will be detected, the sequence variant can be determined by automated nucleotide sequencing of the PCR product. Thus, this strategy will allow elucidation of the specific mutations in most cases, which can then be tested in fetal DNA obtained from chorionic villi or from amniocytes. This approach yielded the identification of 11 previously undescribed mutations in COL7Al in nine of the families in this study (Table 3).

Under ideal conditions, the DNA analysis of the nuclear family, including testing for polymorphic markers and microsatellite repeats as well as mutation detection, can be completed within 2 weeks. Once the DNA analysis of the parents and the previously affected child is completed, the testing of the fetal DNA can be accomplished within $48 \mathrm{hr}$ from the time of the arrival of the sample into the laboratory. Routinely, the test can be confirmed from fetal cells grown either from chorionic villus samples or from amniotic fluid. Since chorionic villus sampling can be performed safely as early as the 10th week of gestation, and amniocentesis is now be- 
ing performed as early as the 12 th week of gestation, the DNA-based prenatal testing can be completed well within the first trimester of gestation.

\section{Advantages of DNA-Based Testing versus Fetal Skin Biopsy}

Up to now, the only available means for prenatal testing for dystrophic EB has been fetal skin biopsy at the 18th-21st week of gestation. The skin biopsy specimens were examined for the level of tissue separation and the quantity and morphology of anchoring fibrils within the dermal-epidermal junction. Since the diagnostic hallmark of the dystrophic forms of EB is abnormalities in the anchoring fibrils, this technique has been a reliable means for prenatal diagnosis of this skin disease. However, the drawbacks of the fetal skin biopsy include the fact that the biopsy is performed relatively late, and termination of the pregnancy, if elected, will take place during the second trimester. Furthermore, the invasive procedure in itself is associated with increased fetal loss. Also, the fetal skin biopsy requires specialized skills which are available only in selected medical centers, and there are relatively few electron microscopists proficient in accurate evaluation of the ultrastructural morphology of the fetal skin. In contrast, chorionic villus sampling and amniocentesis are routine procedures in most medical centers and can be performed in the office setting. Furthermore, PCR amplification of COL7Al sequences, once the design of appropriate primers and PCR amplification conditions have been established, is routinely achievable in most laboratories proficient in molecular genetics. Finally, the turnover time of the PCR-based assay is relatively short, the results being available from fetal DNA within 48 hours, once the mutation and/or haplotype analyses have been performed in parents and the previously affected child. Consequently, it is predictable that the DNA-based testing for RDEB in families at risk for recurrence will replace the invasive fetal skin biopsy in the near future $(29,30)$. Mutation-based DNA testing for the fetal genotype during the first trimester of gestation is advantageous in reducing the period of anxiety and uncertainty on part of the parents.

\section{Suggested Guidelines for DNA-Based Prenatal Diagnosis of RDEB}

In most severe cases, the recessively inherited forms of dystrophic EB present with extreme mutilating scarring of the skin and the gastrointestinal tract, and are frequently associated with premature demise of the affected individuals. The spectrum of severity noted within the dystrophic forms of EB apparently reflects the types and combinations of specific mutations underlying this disease in COL7Al in different families. Therefore, mutation-based DNA testing of RDEB must be specifically designed for each family. Haplotype analysis, using informative singlebase polymorphisms or microsatellite markers has to be undertaken with recognition that rare de novo mutations or parental germ line mosaicism can lead to a false positive prediction of the fetal genotype. It should be noted, however, that in a recessively inherited condition, the haplotype analysis using intragenic markers theoretically cannot result in false negative predictions of the fetal genotype.

Based on these considerations, we propose the following guidelines for DNA-based prenatal diagnosis of RDEB in families at risk for recurrence:

1. The unequivocal diagnosis of dystrophic EB must be established in the previously affected child by electron microscopy and immunofluorescence studies, and a clinical description must be provided.

2. The prediction should optimally be based on demonstration of the presence or absence of specific mutations identified in a previously affected child and in heterozygous parents. If possible, mutation detection should be performed prior to initiation of pregnancy. This approach will facilitate the genotype analysis of the fetal DNA, once the fetal tissue specimen is obtained. Specifically, the analysis can be performed within $48 \mathrm{hr}$ of the arrival of the tissue sample into the laboratory.

3. In case mutations have not been detected or there is not sufficient time to search for mutations, genetic linkage analysis can be utilized, preferentially with intragenic polymorphic markers. In light of the observation that the human COL7Al gene is relatively compact, $\sim 32$ $\mathrm{kb}$ in size (22), the likelihood of a recombination event between the mutation and an intragenic marker is extremely small. These haplotype analyses can be enhanced by utilization of closely linked flanking microsatellite markers (25) that have proven to be highly informative in several families. However, 
if haplotype analysis is performed by using linkage markers and an affected fetus is predicted, this prediction should be confirmed with subsequent fetal skin biopsy to rule out a false positive result due to a de novo mutation in the previously affected child or parental germ line mosaicism.

4. In case of an affected fetus, if the parents are not electing termination of the pregnancy, a Caesarean section is recommended for delivery to minimize birth trauma, which can be extensive and may lead to perinatal demise of the infant.

\section{CONCLUSIONS}

In this study, we have demonstrated the feasibility of DNA-based prenatal testing for RDEB in families at risk for recurrence. The advances of molecular biology have now provided a basis for direct mutation detection in the affected families, and this information is not only useful for prenatal or preimplantation diagnosis, but is also a prerequisite for the future design of molecular biological approaches for gene therapy for this devastating skin disease.

\section{ACKNOWLEDGMENTS}

We sincerely appreciate the willingness of RDEB patients and their families to participate in this study. We would like to thank the following physicians and genetic counselors: Family A: Lori Finn, M.S., and Eugene Pergament, M.D., Northwestern Memorial Hospital, Chicago, IL; Family B: Annette Yen-Batey, M.S., and David R. Witt, M.D., Kaiser Permanente Medical Group, San Jose, CA, and Sheila Gibbons, L.V.N, and Lexie Nall, Ph.D., of the National EB Registry, Stanford University School of Medicine, Stanford, CA; Family C: Gregory Ryan, M.D., and David Chitayat, M.D., University of Toronto Hospital, Ontario; Family D: Cindy Quinn, M.S., and Sterling McColgin, M.D., University of Colorado Health Sciences Center, Denver, CO; Family E: Shearon Roberts, M.S., and Karen Holbrook, Ph.D., University of Florida, Gainesville, FL; Family F: Valerie Hani, M.S., Dartmouth Hitchcock Medical Center, Lebanon, NH, Andrew N. Lin, M.D., Mary D. Brust, R.N., and the late D. Martin
Carter, M.D., Ph.D., National EB Registry, Rockefeller University, New York, NY; Family G: Ishwar C. Verma, M.D., F.R.C.P., All India Institute of Medical Sciences, New Delhi, India; Family H: Shearon Roberts, M.S., University of Florida, Gainesville, FL, and Jo-David Fine, M.D., M.P.H., National EB Registry, University of North Carolina, Chapel Hill, NC; Family I: Takeji Nishikawa, M.D., Ph.D., Keio University School of Medicine, Tokyo, Japan, and Kaoru Suzumuri, M.D., Ph.D., Nagoya City University Medical School, Nagoya, Japan; Family J: Laura Turlington, M.S., Washington University School of Medicine, St. Louis, MO. We gratefully acknowledge the assistance of National EB Registry for evaluation of the patients. Electron microscopic and immunohistochemical analyses were performed by Wedad Hanna, M.D., Women's College Hospital, Toronto, Ontario (Family C); Byron P. Croker, M.D., Ph.D., University of Florida, Gainesville, FL, and Robert A. Briggaman, M.D., University of North Carolina, Chapel Hill, NC (Family E); Jo-David Fine, M.D., M.P.H., National EB Registry, University of North Carolina, Chapel Hill, NC, and Lynne T. Smith, Ph.D., National EB Registry, University of Washington, Seattle, WA (Family F); Jo-David Fine, M.D., M.P.H., The National EB Registry, University of North Carolina, Chapel Hill, NC (Family H). We thank Xin Zhang and Yili $\mathrm{Xu}$ for technical help, and Tamara Alexander and Beth Attig for secretarial assistance. The Automated DNA Sequencing Core of the Jefferson Cancer Institute, directed by Dr. Hansjürg Alder, performed direct PCR sequence analysis.

This work was supported by grants from USPHS, National Institutes of Health (POIAR38923, P01-AR41045, and N01-AR2-2204), the March of Dimes Birth Defects Foundation, and the Dystrophic Epidermolysis Bullosa Research Association of America. AMC was supported by the Society for Investigative Dermatology Research Career Development Award from the Dermatology Foundation.

\section{REFERENCES}

1. Lin AM, Carter DM. (1992) Epidermolysis Bullosa: Basic and Clinical Aspects. Springer-Verlag, New York.

2. Fine JD, Bauer EA, Briggaman RA, et al. (1991) Revised clinical and laboratory criteria for subtypes of inherited epidermolysis bullosa: A consensus report by the subcommittee on diagnosis and classification of the 
National Epidermolysis Bullosa Registry. $J$. Am. Acad. Dermatol. 24: 119-153.

3. Uitto J, Christiano AM. (1992) Molecular genetics of the cutaneous basement membrane zone. Perspectives on epidermolysis bullosa and other blistering skin diseases. $J$. Clin. Invest. 90: 687-692.

4. Fuchs E. (1992) Genetic skin disorders of keratin. J. Invest. Dermatol. 99: 671-674.

5. Burgeson RE, Chiquet M, Deutzmann R, et al. (1994) A new nomenclature for laminins. Matrix Biol. 14: 209-211.

6. Pulkkinen L, Christiano AM, Airenne $\mathrm{T}$, Haakana H, Tryggvason K, Uitto J. (1994) Mutations in the $\gamma 2$ chain gene (LAMC2) of kalinin/laminin 5 in the junctional forms of epidermolysis bullosa. Nature Genet. 6: 293298.

7. Aberdam D, Galliano M-F, Vailly J, et al. (1994) Herlitz's junctional epidermolysis bullosa is genetically linked to mutations in the gene for the $\gamma 2$ subunit (LAMC2) of nicein/kalinin (laminin 5). Nature Genet. 6: 299-304.

8. Pulkkinen L, Christiano AM, Gerecke D, Burgeson RE, Pittelkow MR, Uitto J. (1994) A homozygous nonsense mutation in the $\beta 3$ chain gene of laminin 5 (LAMB3) in Herlitz junctional epidermolysis bullosa. Genomics 24: 357-360.

9. Uitto J, Pulkkinen L, Christiano AM. (1994) Molecular basis of the dystrophic and junctional forms of epidermolysis bullosa: Mutations in the type VII collagen and kalinin (laminin 5) genes. J. Invest. Dermatol. 103: 39S-46S.

10. McGrath JA, Ishida-Yamamoto A, O'Grady A, Leigh IM, Eady RAJ. (1993) Structural variations in anchoring fibrils in dystrophic epidermolysis bullosa: correlation with type VII collagen expression. J. Invest. Dermatol. 100: $366-372$.

11. Christiano AM, Greenspan DS, Hoffman GG, et al. (1993) A missense mutation in type VII collagen in two affected siblings with recessive dystrophic epidermolysis bullosa. Nature Genet. 4: 62-66.

12. Hilal L, Rochat A, Duquesnoy P, et al. (1993) A homozygous frameshift mutation in COL7Al predicting a truncated protein in the Hallopeau-Siemens form of recessive dystrophic epidermolysis bullosa. Nature Genet. 5: 287-293.

13. Christiano AM, Anhalt G, Gibbons S, Bauer EA, Uitto J. (1994) Premature termination codons in the type VII collagen gene (COL7Al) underlie severe, mutilating recessive dystrophic epidermolysis bullosa. Genomics 21: 160-168.

14. Hovnanian A, Hilal L, Blanchet-Bardon C, et al. (1994) Recurrent nonsense mutations within the type VII collagen gene in patients with severe recessive dystrophic epidermolysis bullosa. Am. J. Hum. Genet. 55: 289-296.

15. Christiano AM, Ryynänen M, Uitto J. (1994) Dominant dystrophic epidermolysis bullosa: Identification of a glycine-to-serine substitution in the triple-helical domain of type VII collagen. Proc. Natl. Acad. Sci. U.S.A. 91: 3549-3553.

16. Christiano AM, Suga Y, Greenspan DS, Ogawa H, Uitto J. (1995) Premature termination codons on both alleles of the type VII collagen gene (COL7Al) in three brothers with recessive dystrophic epidermolysis bullosa. J. Clin. Invest. 95: 1328-1334.

17. Christiano AM, Uitto J. (1993) DNA-based prenatal diagnosis of heritable skin diseases. Arch. Derm. 29: 1455-1459.

18. Eady RAJ, Gunner DB, Tidman MJ. (1984) Rapid processing of fetal skin for prenatal diagnosis by light and electron microscopy. J. Clin. Pathol. 37: 633-638.

19. Heagerty AHM, Kennedy AR, Gunner DB, Eady RAJ. (1986) Rapid prenatal diagnosis and exclusion of epidermolysis bullosa using novel antibody probes. J. Invest. Dermatol. 86: 603-605.

20. Uitto J, Christiano AM. (1994) Molecular basis of the dystrophic forms of epidermolysis bullosa: Mutations in the type VII collagen gene. Arch. Dermatol. Res. 287: 16-22.

21. Christiano AM, Greenspan DS, Lee S, Uitto J. (1994) Cloning of human type VII collagen. Complete primary sequence of the $\alpha \mathrm{l}(\mathrm{VII})$ chain and identification of intragenic polymorphisms. J. Biol. Chem. 269: 20256-20262.

22. Christiano AM, Hoffman GG, Chung-Honet LC, et al. (1994) Structural organization of the human type VII collagen gene (COL7Al), comprised of more exons than any previously characterized gene. Genomics 21: 169-179.

23. Parente MG, Chung LC, Ryynänen J, et al. (1991) Human type VII collagen: cDNA cloning and chromosomal mapping of the gene. Proc. Natl. Acad. Sci. U.S.A. 88: 6931-6935.

24. Sambrook J, Fritsch EF, Maniatis T. (1989) Molecular Cloning. A Laboratory Manual. Cold 
Spring Harbor Laboratory Press, Cold Spring Harbor, NY.

25. Naylor SL, Buys CHCM, Carritt B. (1994) Report of the Fourth International Workshop on Human Chromosome 3 Mapping 1993. Cytogen. Cell Genet. 65: 1-50.

26. Christiano AM, Chung-Honet LC, Hovnanian A, Uitto J. (1992) PCR-based detection of two exonic polymorphisms in the human type VII collagen gene (COL7Al) at 3p21.1. Genomics 4: 827-828.

27. Hovnanian A, Duquesnoy P, Blanchet-Bardon C, et al. (1992) Genetic linkage of recessive dystrophic epidermolysis bullosa to the type VII collagen gene. J. Clin. Invest. 90: 1032-1036. 28. Dunnill MGS, Richards AJ, Milana G, et al.
(1994) Genetic linkage to the type VII collagen gene (COL7A1) in 26 families with generalised recessive dystrophic epidermolysis bullosa and anchoring fibril abnormalities. $J$. Med. Genet. 31: 745-748.

29. Christiano AM, Uitto J. (1996) Molecular diagnosis of inherited skin diseases: The paradigm of dystrophic epidermolysis bullosa. Advances Dermatol. 11: 199-213.

30. Hovnanian A, Hilal L, Blanchet-Bardon C, et al. (1995) Prenatal diagnosis of the hallopeau siemens form of recessive dystrophic epidermolysis bullosa by type VII collagen gene analysis in six pregnancies at risk for recurrence. J. Invest. Dermatol. 104: 456-461.

Contributed by D. J. Prockop on September 11, 1995. 